\section{Feel for vertebrates}

\section{D.R. Newth}

\section{Longman Illustrated Animal \\ Encyclopedia. \\ Edited by Philip Whitfield.}

Longman: 1984. Pp.260. f25. In the

United States the Macmillan Illustrated

Animal Encyclopedia (Macmillan, \$35).

Do NOT be deceived by the title's implied claim that this book surveys the whole animal kingdom, and still less by the dustcover which calls it a "visual who's who of all the world's creatures". Instead, more modestly, it treats of some 2,000 species of living vertebrate animal. Each is granted a reproduction, in colour, of a painting and a short (80-300-word) non-technical description. The aim has been to include at least one species from each tetrapod family and at least one from each order of the fishes. Some higher taxa are briefly described and mammals, birds, reptiles, amphibians and fishes are each introduced by a short general account.

The pictures are certainly both vivid and decorative, but they are not always sufficiently detailed or accurate to match good colour photographs (although, of course, good photographs would not always be easy to obtain). Since they are rationed at one to each species there is no place for larval or juvenile forms, and where sexual dimorphism is marked the more flamboyant sex is chosen for show. The textual material is necessarily basic, but has lacked critical revision to eliminate minor errors and other lapses from grace. Of the latter, the heading given to the section on reptiles, which boldly proclaims them to be "survivors from a prehistoric age', seems typical. It is true, but true also of every other class of living animal.

Its defects apart, it is unlikely that this book will be of value to students of vertebrate zoology. On the other hand it may well attract and instruct non-scientists and give them a feel for the range of size, shape, coloration and lifestyle of the vertebrates and some idea of their relationships. This, presumably, was the intention of the publishers, but it is still difficult to imagine whose coffee table the book is designed to grace.

D.R. Newth was formerly Regius Professor of Zoology at the University of Glasgow.

\section{Down under standard}

\section{G.B. Corbet}

\section{The Complete Book of Australian Mammals. \\ Edited by Ronald Strahan. \\ Angus \& Robertson: 1984. Pp.529. £25.}

THE past 20 years have witnessed a revolution in the application of highquality colour printing to natural history publishing. In that same period the production of authoritative syntheses of biological data on major taxonomic groups and faunal regions has achieved increasingly high standards. But with some exceptions, the economics of publishing have usually prevented these advances from coming together. Writers and editors of scholarly works are commonly frustrated by the impracticality of including colour illustrations, even when these would enormously enhance the information content, whilst popular works with adequate, and often superb, colour illustration rarely carry a text that meets the standards required of a scientific source book.

The exceptions have mostly dealt with subjects such as molluscs and butterflies, where the ease of photographing preserved specimens and the popular interest have combined to make good illustrated handbooks feasible. The elusiveness of most mammals makes them a much more difficult subject for such treatment, and so The Complete Book of Australian Mammals is something of a pioneer. It is based upon a
National Photographic Index of Australian Wildlife established by the Australian Museum, Sydney, and includes colour photographs of living animals of all but 22 of the 273 species included. Considering the rarity and elusiveness of many Australian mammals, marsupials and placentals, this is quite an achievement.

Although the convergence and parallelism shown by the Australian marsupials in relation to placental mammals elsewhere are a standard ingredient of evolutionary teaching, the illustration of almost all the 129 species in one work enables this phenomenon to be appreciated and indeed studied in a way that has not hitherto been possible.

The text is the work of 107 different authors with first-hand research experience, and is up-to-date and authoritative, summarizing habitat, ecology, reproduction and behaviour. The reference value is greatly enhanced by a clear distribution map for each species. Although facts are not individually documented with regard to source, some bibliographical references are given for each species, providing at least an entry into the literature.

While it falls short of being a really comprehensive illustrated handbook - it does not, for example, cover critical identification requiring internal characters this book nevertheless sets a standard that has not yet been matched in areas such as Europe and North America where the mammal fauna is much better known.

G.B. Corbet is in the Department of Central Services at the British Museum (Natural History), London.

\section{Everyone's stunning animals}

\section{Carolyn M. Crockett}

The Encyclopedia of Mammals.

Edited by David Macdonald.

George Allen \& Unwin/Facts on

File: 1984. Pp. 895. In Britain published in two volumes, 125 each. In the United States as a single volume, $\$ 45$.

HERE is a volume whose illustrations and photographs are a pleasure to peruse. What makes it an especially worthwhile purchase, however, is the authoritative and well-written text. David Macdonald has orchestrated a lively collection of articles, assembling contributions from 180 experts from around the world; the result will appeal to anyone interested in animals the lay public, students and their teachers, and professional zoologists.

The book describes the appearance, diet, social behaviour, anatomical characteristics and peculiarities of all mammal groups. For some, illustrations and descriptions of extinct ancestors are also included. The entries are all short, ranging from a small box on a specific topic to several pages of description of a mammal group, usually at the family or subfamily level. This makes ideal reading with morning coffee or afternoon tea, since the individual passages hang together and can be read in just a few minutes.

The book begins with a dozen or so pages describing mammals in general, summarizing their evolution, characteristics and taxonomy. The remainder is divided into accounts of each order and concludes with a bibliography, a glossary of nearly 500 terms that might not be familiar to the lay reader, and an index. For most orders, a complete listing and short description of each species is given in a section of the main text. A few orders, such as the Rodentia, Chiroptera and Marsupialia, are described down to the genus or tribe level, while a complete listing of species is presented in an appendix.

To give an indication of the richness of this volume, let me summarize the section on the Capuchin-like monkeys (Cebidae). It begins with a box containing a distribution map and a silhouette scale-drawing comparing the size of a man with the largest and the smallest members of this monkey group. The text includes a general description of the Cebids, their adaptations (such as prehensile tails for the larger species) and their social organization. A beautiful colour drawing (one of many excellent ones by Priscilla Barrett) accurately depicts nine species in various postures; by showing different - yet typical - behaviours, this and the other plates provide more information than do most field guides. Next comes a more traditional description of each species, including common name, 